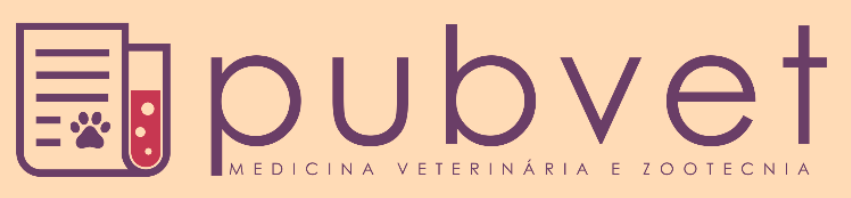

https://doi.org/10.31533/pubvet.v15n12a983.1-8

\title{
Ensilagem e os componentes fibrosos dos alimentos volumosos
}

\author{
Frederico Patrus Ananias de Assis Pires ${ }^{1 *} \bullet$, Lúcio Carlos Gonçalves ${ }^{2}{ }^{\bullet}$, Alan Figueiredo de \\ Oliveira $^{3 \bullet}$, Guilherme Lobato Menezes ${ }^{1 \bullet}$, Pamella Grossi de Sousa ${ }^{\circ}{ }^{\circ}$ (D, Rafael Araújo de \\ Menezes $^{4}{ }^{\circ}$ (D), João Vitor Araújo Ananias ${ }^{\circ}$
}

${ }^{1}$ Doutorando em Nutrição Animal, Departamento Zootecnia, Universidade Federal de Minas Gerais EV UFMG, Belo Horizonte - MG, Brasil. ${ }^{2}$ Prof. Adjunto, Departamento de Zootecnia, Universidade Federal de Minas Gerais EV UFMG, Belo Horizonte - MG, Brasil.

${ }^{3}$ Doutorando em Produção Animal, Departamento Zootecnia, Universidade Federal de Minas Gerais EV UFMG, Belo Horizonte - MG, Brasil. ${ }^{4}$ Mestrando em Nutrição Animal, Departamento Zootecnia, Universidade Federal de Minas Gerais EV UFMG, Belo Horizonte-MG, Brasil. ${ }^{5}$ Graduando em Medicina Veterinária, Faculdades Unidas do Norte FUNORTE, Montes Claros - MG, Brasil.

*Autor para correspondência, E-mail: fredericopires@vetufmg.edu.br

Resumo. A ensilagem é o método mais usado para a conservação dos alimentos volumosos. O principal componente nutricional desses alimentos é a fibra. Porém os impactos da ensilagem sobre a fibra são variáveis. Nesse sentido, pode-se constatar aumentos proporcionais na participação de fibra em detergente neutro (FDN) das silagens, devido ao consumo de proteínas e carboidratos solúveis durante o processo fermentativo. A intensidade desse aumento depende das características intrínsecas das forrageiras usadas, da qualidade e do tipo de fermentação que ocorre no silo. Entretanto, deve-se considerar que o processo fermentativo também pode atuar diretamente sobre os componentes fibrosos. Devido a suas características bioquímicas, essa atuação geralmente ocorre sobre as hemiceluloses, pelo mecanismo de hidrólise ácida. Portanto, a ensilagem também pode reduzir os teores de FDN das silagens. A queda nos teores de FDN é constada muitas vezes em processos fermentativos de qualidade com baixas perdas de matéria seca (MS). Além disso, deve-se ressaltar que a hidrólise ácida das hemiceluloses apresenta importantes implicações nutricionais, levando à diminuição na digestibilidade da fibra e ao aumento na digestibilidade da matéria orgânica (MO) das silagens. Observa-se com os resultados discutidos que a qualidade do processo fermentativo é determinante nas consequências da ensilagem sobre os componentes fibrosos dos alimentos volumosos.

Palavras chave: Forragem, hemiceluloses, ruminantes

\section{Silage and the fibrous components of bulky foods}

Abstract. Silage is the most used method for preserving bulky foods. The main nutritional
component of these foods is the fiber. However, the impacts of ensilage on the fiber are
variable. In this sense, it can be seen proportional increases in the participation of neutral
detergent fiber (FDN) in the silages due to the consumption of proteins and soluble
carbohydrates during the fermentation process. The intensity of this increase depends on
the intrinsic characteristics of the forages used, the quality and type of fermentation that
take place in the silo. However, it should be considered that the fermentation process can
also act directly on the fibrous components. Due to its biochemical characteristics, this
action usually occurs on hemicelluloses, through the acid hydrolyses mechanism.
Therefore, the ensilage can also reduce the FDN contents of silages. The drop in the FDN
contents is often seen in quality fermentation processes with low dry matter (DM) losses.
Furthermore, it should be noted thar the acid hydrolyses of hemicelluloses has important
nutritional implications, leading to a decrease in fiber digestibility and an increase in
organic matter (MO) digestibility of the silages. It is observed with the results discussed 
that the quality of the fermentation processes is decisive in the consequences of ensiling on the fibrous components of bulky foods.

Keywords: Forage, hemicelluloses, ruminants

\section{Ensilaje y componentes fibrosos de alimentos voluminosos}

Resumen. El ensilaje es el método más utilizado para conservar alimentos voluminosos. El principal componente nutricional de estos alimentos es la fibra. Sin embargo, los impactos del ensilaje sobre la fibra son variables. En este sentido, se pueden ver incrementos proporcionales en la participación de fibra en detergente neutra (FDN) en los ensilajes debido al consumo de proteínas y carbohidratos solubles durante el proceso de fermentación. La intensidad de este aumento depende de las características intrínsecas de los forrajes utilizados, la calidad y el tipo de fermentación que se realiza en el silo. Sin embargo, se debe considerar que el proceso de fermentación también puede actuar directamente sobre los componentes fibrosos. Por sus características bioquímicas, esta acción suele darse sobre las hemicelulosas, a través del mecanismo de hidrólisis ácida. Por lo tanto, el ensilaje también puede reducir el contenido de FDN de los ensilajes. La caída en el contenido de FDN se observa a menudo en procesos de fermentación de calidad con bajas pérdidas de materia seca (MS). Además, cabe señalar que la hidrólisis ácida de las hemicelulosas tiene importantes implicaciones nutricionales, lo que conduce a una disminución de la digestibilidad de la fibra y un aumento de la digestibilidad de la materia orgánica (MO) en los ensilajes. Se observa con los resultados comentados que la calidad del proceso de fermentación es determinante en las consecuencias del ensilado sobre los componentes fibrosos de los alimentos voluminosos.

Palabras clave: Forrajes, hemicelulosas, rumiantes

\section{Introdução}

A ensilagem é um método de conservação que se baseia na fermentação lática dos alimentos em ambiente anaeróbico (McDonald, 1981). Esse método é amplamente utilizado na conservação de alimentos volumosos como uma estratégia para alimentação dos rebanhos em períodos críticos do ano. Com isso destaca-se que a ensilagem é o principal método de conservação de forragens em diversas partes do mundo (Bolsen et al., 1996). Além disso, em comparação com outros métodos, a ensilagem é o que retém maior quantidade de nutrientes do material de origem (Woolford \& Pahlow, 1998).

O principal nutriente das silagens confeccionadas com alimentos volumosos é a fibra, geralmente mensurada como fibra em detergente neutro (FDN) (NRC, 2000). Nutricionalmente, a fibra é definida como a fração dos alimentos que é lentamente digerida ou indigestível, com capacidade de ocupar espaço no trato digestivo. Assim, sabe-se que esse nutriente possui importante relação com diversos aspectos nutricionais, como a concentração energética dos alimentos, o consumo de matéria seca (Mertens, 1994), e com a manutenção da função ruminal (Alves et al., 2016). Portanto, é fundamental entender os aspectos que podem interferir nos teores e na digestibilidade da fibra das silagens.

O processo fermentativo é responsável pela maior parte das modificações químicas que ocorrem nas forrageiras após a ensilagem. Todavia, diversos fatores podem interferir não só na qualidade do processo fermentativo, mas também nas suas consequências. A literatura demonstra que a ensilagem pode resultar na elevação, na redução ou não interferir na concentração e/ou na digestibilidade da fibra. Objetivou-se discutir os principais efeitos da ensilagem sobre as frações fibrosas dos alimentos volumosos

\section{Processo fermentativo e as elevações proporcionais dos teores de fibra}

O processo de produção de silagem pode ser dividido em quatro fases: aeróbica, fermentativa, estabilidade e desabastecimento (Bolsen et al., 1996). A fase aeróbica inclui as etapas desde a colheita até a vedação dos silos. Nessa fase, a presença do oxigênio possibilita que dois processos atuem: proteólise e respiração. Esses processos ocorrem pela ação das enzimas dos vegetais e dos microrganismos aeróbicos e anaeróbicos facultativos (McDonald, 1981). Após a vedação dos silos 
inicia-se a fase fermentativa. Nessa fase, as bactérias anaeróbicas usam os carboidratos solúveis e a água como substratos e produzem ácidos, principalmente o lactato e o acetato. Com o acúmulo desses ácidos, o pH da silagem cai até atingir a fase estável (Muck, 2010) e considera-se que poucas transformações ocorram até o momento de abertura do silo (desabastecimento).

Nota-se que durante o processo de ensilagem, a atuação dos microrganísmos ocorre com o consumo de componentes, especialmente dos carboidratos solúveis e das proteínas. Portanto, a ensilagem pode aumentar de forma proporcional os teores de FDN e de fibra em detergente ácido (FDA) dos alimentos (Del Valle et al., 2018). Esse aumento proporcional geralmente é constatado em situações que favoreçam as perdas de MS. Essas situações podem estar relacionadas a falhas no processo de produção das silagens como atrasos nas operações de enchimento e vedação com aumento das perdas aeróbicas. Além disso, determinadas características bromatalógicas das forrageiras como os níveis de umidade no momento de corte também podem ser determinantes. Sabe-se que a elevada umidade favorece a fermentação butirica, uma rota fermentativa relacionada a elevada proteólise e perdas pela produção de efluentes (lixiviação de componentes nutricionais) (McDonald, 1981).

Ressalta-se ainda a importância de outros aspectos da forrageira como o poder tampão, a concentração de carboidratos solúveis e a microbiota epifítica. Essa importância é exemplificada pelo elevado número de trabalhos que constataram aumentos expressivos nos teores de FDN e de FDA com a ensilagem da cana de açucar (Ávila et al., 2008; Del Valle et al., 2018). A cana de açúcar caracterizase pela elevada concentração de sacarose, que durante a ensilagem, é intensamente usada para obtenção de energia pelas leveduras por meio da fermentação alcóolica (Del Valle et al., 2018). A fermentação alcóolica consiste na transformação da glicose em duas moléculas de dióxido de carbono $\left(\mathrm{CO}_{2}\right)$ e de etanol. Com isso, durante a fase fermentativa das silagens de cana de açúcar em especial, as perdas de MS na forma de gases são ainda mais elevadas, o que favorece o aumento da concentração dos componentes fibrosos (Silva et al., 2018).

Estudos conduzidos com outras forrageiras também evidenciaram elevações nos conteúdos de fibra das silagens. Leão et al. (2017) avaliaram a composição nutricional de silagens de cereais de inverno submetidas a 60, 120 e 180 dias de estocagem no silo. Os cereais avaliados foram: Trigo (Triticum aestivum), cevada (Hordeum vulgare), aveia branca (Avena sativa), aveia preta (Avena strigosa) e triticale (Triticosecale). Todas as silagens avaliadas apresentaram aumento gradativo das concentrações de FDN. Os maiores aumentos foram constatados para as silagens de aveia preta, com incrementos de $12,7 \%$ entre 60 e 180 dias de estocagem no silo. Os autores também constataram maiores perdas de matéria seca com o aumento do tempo de estocagem. Esses resultados demonstram que as transformações podem continuar ocorrendo por longos períodos de armazenamento e de forma distinta entre as forrageiras. Todavia deve-se considerar que possíveis problemas durante o armazenamento que levam a exposição ao ar, também podem produzir esses resultados.

Considerando-se os aspectos discutidos, deve-se frisar que a elevação proporcional da fibra se relaciona com a queda no valor nutricional dos alimentos volumosos, devido aos aspectos nutricionais deste componente (baixa concentração de energia, lenta utilização e relação com limitação de consumo). Entretanto, além das possíveis alterações proporcionais citadas, sabe-se que o processo fermentativo também pode atuar de forma direta sobre os componentes fibrosos. Assim, estudos demonstraram que a ensilagem também pode reduzir o conteúdo de fibra dos alimentos, especialmente como consequência da hidrólise ou solubilização das hemiceluloses (Gerlach et al., 2018; Köhler et al., 2019).

\section{Hidrólise das hemiceluloses e os teores de fibra das silagens}

As hemiceluloses são classificadas como polissacarídeos estruturais e estão incluidas na FDN, juntamente com a celulose e a lignina (Van Soest, 1994). As hemiceluloses caracterizam-se pela estrutura amorfa com cadeia ramificada e podem conter diferentes componentes como as pentoses ( $\beta$ $D$-xilose, $\alpha$-L-arabinose), as hexoses ( $\beta$-D-manose, $\beta$-D-glicose, $\alpha$-D-galactose) e os ácidos urônicos. Devido à essas características, as hemiceluloses oferecem menor resistência a quebra em comparação com outros componentes altamente polimerizados e cristalinos como a celulose (O'sullivan, 1997). Logo, a redução dos teores de FDN é constatada com maior frequência do que as reduções dos teores de FDA (celulose e lignina) pelo processo de ensilagem (Köhler et al., 2019). 
A hidrólise das hemiceluloses se refere à quebra de ligações do tipo ester entre os seus componentes, como a xilose e arabinose e a lignina (Dewar et al., 1963). Essa quebra pode ocorrer pela ação de fungos, enzimas bacterianas (homo e heteroláticas) e/ou pela reação ácida com os ácidos orgânicos produzidos durante a fermentação (McDonald, 1981). É importante destacar que a redução dos teores de fibra é usualmente observada em materiais que apresentaram processos fermentativos de qualidade. Nesses materiais a fase fermentativa é caracterizada por um rápido e intenso abaixamento do $\mathrm{pH}$ e elevada produção de ácidos orgânicos (Kung Junior et al., 2018). Sabe-se que as hemicelulases vegetais e bacterianas apresentam melhor atuação sob pH 6 e que os baixos valores de $\mathrm{pH}$ inibem o crescimento dos fungos capazes de hidrolisar as hemiceluloses. Portanto, a reação de hidrólise ácida das hemiceluloses é considerada como o principal mecanismo responsável pela redução dos teores de FDN das silagens (McDonald, 1981).

Outro aspecto relevante é o de que o processo de hidrolise das hemiceluloses geralmente ocorre logo nos primeiros dias após a ensilagem. Gerlach et al. (2018) avaliaram a composição química das silagens produzidas com nove híbridos de milho armazenadas por 30, 60, 90 e 120 dias. Os autores encontraram redução nos valores de FDN de 38,9\% no material fresco para 36,1\% nas silagens submetidas a 30 dias de armazenamento, o que representa uma diferença de 7,8\%. Entretanto, não foram observadas diferenças nas concentrações de FDN entre as silagens submetidas ao aumento do tempo de estocagem. Herrmann et al. (2011) obtiveram resultados semelhantes em silagens de milho e constataram uma redução significativa dos teores de FDN apenas nos primeiros 10 dias após a ensilagem.

Por outro lado, Naeini et al. (2014) em um trabalho com sorgo sacarino não encontraram diferenças nas concentrações de FDN entre a forragem fresca e a sua silagem com 30 dias de estocagem. Entretanto, foi constada redução de 54,4 para 49,5\% nos teores de FDN das silagens avaliadas com 30 e 120 dias respectivamente. Essas reduções também foram atribuídas ao processo de hidrólise ácida das hemiceluloses. Além disso, também foram encontradas alterações nos parâmetros fermentativos com o aumento do tempo de estocagem no silo. Dessa forma, o processo a quebra das hemiceluloses também pode ocorrer após longos períodos de armazenamento das silagens.

Uma possível explicação para a divergência de resultados entre os trabalhos (efeito de tempo de armazenamento), pode estar no método estatístico utilizado para a análise dos dados. No estudo conduzido por Gerlach et al. (2018), os dados foram comparados por teste de médias, e mesmo observando-se menores valores numéricos nos valores de FDN com o aumento do tempo de armazenamento, não houveram diferenças estatísticas. Já no trabalho de Naeini et al. (2014) utilizaram o método de regressão linear para avaliação do efeito do tempo de armazenamento sobre as variáveis analisadas. É importante considerar também a diferença entre forrageiras usadas nos dois experimentos bem como as condições experimentais inerentes em cada trabalho.

Ainda nesse contexto, deve-se ressaltar que diversos trabalhos não encontraram modificações nos teores de fibras com o processo de ensilagem (comparação entre forrageira original e a silagem) de diferentes forrageiras (Bueno et al., 2020; Ferraretto et al., 2015; Santos \& Kung Junior, 2016). Portanto, nem sempre o processo de hidrólise das hemiceluloses pode ocorrer ou ser intenso a ponto de modificar significativamente as concentrações de FDN das silagens. Deve-se considerar que processos fermentativos associados a elevadas perdas de MS podem prejudicar a identificação dos impactos da hidrólise das hemiceluloses sobre os teores de FDN. Além disso, assim como nas perdas fermentativas, diferenças químicas entre as forrageiras interferem na magnitude do processo de redução da FDN. Der Bedrosian et al. (2012) avaliaram as características fermentativas e nutricionais das silagens de híbridos de milho convencionais ou BMR em diferentes tempos de abertura até atingir 360 dias de estocagem nos silos. Os autores não encontraram diferenças nas concentrações de FDN em nenhuma das silagens avaliadas, porém, constataram menores teores de hemiceluloses para a silagens confeccionadas com os híbridos BMR. A justificativa para os resultados obtidos foi atribuída ao menor teor de lignina desses híbridos o que pode ter favorecido o processo de solubilização das hemiceluloses.

\section{Hidrólise das hemiceluloses e o valor nutricional das silagens}

Em alguns experimentos o processo de ensilagem das forrageiras proporcionou elevações da digestibilidade da fibra. Hallada et al. (2008) verificaram aumento constante na degradabilidade in situ da FDN (D-FDN) em silagens de milho, com elevações de 1,2 unidades percentuais por mês até atingir 
platô nas silagens com 330 dias de estocagem. Uma possivel explicação para essas elevações diz respeito a mudanças microbiológicas que podem ocorrer nas silagens com o aumento do tempo de estocagem. Segundo Schmidt et al. (2009), entre essas mudanças, observa-se que a bacteria Lactobacillus Buchneri torna-se a bactéria ácido lática dominante em processos fermentativos prolongados. Nesse contexto, algumas cepas de L. buchneri são capazes de produzir a enzima esterase de ácido ferúlico que possui potencial para melhorar a digestibilidade da fibra (Muck et al., 2018).

No entanto, considera-se que os efeitos da enzima esterase de ácido ferúlico sobre a digestibilidade da fibra são inconsistentes (Lynch et al., 2015) e que os fatores que influenciam na produção e atuação dessa enzima ainda não são bem compreendidos (Muck et al., 2018). Além disso, a maior parte dos trabalhos disponíveis na literatura demonstraram que quase sempre, o processo de ensilagem está relacionado a redução da digestibilidade da fibra (Kung Junior et al., 2018; Udén, 2018). A principal justificativa da redução da digestibilidade da fibra é a de que as hemiceluloses, principais componentes fibrosos alterados pelo processo fermentativo, também são os elementos que apresentam maior potencial de digestão dentro da FDN (Mason \& Stuckey, 2016). Dessa forma, o restante da fibra que permanece inalterada pelo processo fermentativo geralmente apresenta menor digestibilidade.

Weinberg \& Chen (2013) encontraram expressivas reduções nos valores de digestibilidade in vitro da FDN (DIVFDN) em silagens de milho. Os valores de DIVFDN reduziram de 48,3\% na forragem fresca para $41,7 \%$ nas silagens, com apenas sete dias de fermentação no silo, o que representa uma redução de 14,9\%. O tempo de estocagem no silo também alterou os valores de DIVFDN das silagens e os valores mínimos observados foram de 31,9\% nas silagens com seis meses de armazenamento. Entretanto, Kung Junior et al. (2018) em estudo de revisão demonstraram que geralmente a redução dos valores de DIVFDN é discreta e ocorre apenas nos primeiros meses após a ensilagem (Tabela 1). É importante destacar também que assim como nos teores de FDN, muitas vezes reduções na DIVFDN não são constatadas, como observado no estudo conduzido por Bueno et al. (2020). Diferenças químicas e microbiológicas entre as silagens podem ser responsáveis por essas divergências na literatura.

Tabela 1. Valores de digestibilidade da FDN ( $\%$ da FDN) em silagens de milho com diferentes tempos de armazenamento (Kung Junior et al., 2018).

\begin{tabular}{|c|c|c|c|c|c|c|c|c|c|c|}
\hline \multirow{2}{*}{ Fonte } & \multicolumn{9}{|c|}{ Tempo de armazenamento, dias } & \multirow{2}{*}{-Valor de $\mathrm{p}$} \\
\hline & 0 & 30 & 45 & 60 & 90 & 120 & 150 & 180 & 240 & \\
\hline Cherney et al. $(\underline{2007})^{1}$ & 56 & 50 & - & - & - & - & - & - & - & 0,001 \\
\hline Der Bedrosian et al. $(\underline{2012})^{2}$ & 62 & - & 60 & - & 60 & - & - & 59 & - & 0,01 \\
\hline Ferraretto et al. $(\underline{2015})^{3}$ & 57 & 56 & - & - & - & 55 & - & - & 56 & $\mathrm{NS}^{4}$ \\
\hline Hunt et al. $(\underline{1993})^{5}$ & 73 & - & - & 71 & - & - & - & - & - & NS \\
\hline Sanderson $(\underline{1993})^{5}$ & 66 & - & 62 & - & - & - & - & 63 & - & NS \\
\hline Young et al. $(\underline{2012})^{3}$ & 64 & - & 61 & - & - & - & 60 & - & - & 0,02 \\
\hline
\end{tabular}

${ }^{1}$ Digestibilidade ruminal in vitro. da FDN. $48 \mathrm{~h}$ de incubação. Amostras moídas a $1 \mathrm{~mm}$. ${ }^{2}$ Digestibilidade ruminal in vitro. da FDN. $30 \mathrm{~h}$ de incubação. Amostras moídas a 2 mm. ${ }^{3}$ Digestibilidade ruminal in vitro da FDN. $30 \mathrm{~h}$ de incubação. Amostras moídas a $1 \mathrm{~mm} .{ }^{4}$ Não significativo. ${ }^{5}$ Digestibilidade ruminal in vitro da FDN. 48 h de incubação. Amostras moídas a 2 mm.

Apesar dos efeitos geralmente negativos sobre a digestibilidade da fibra, a hidrólise das hemiceluloses pode estar relacionada ao aumento da digestibilidade da matéria orgânica (Der Bedrosian et al., 2012), como consequência da elevação da concentração de carboidratos solúveis na massa ensilada (Gerlach et al., 2018; Weinberg \& Chen, 2013).

Köhler et al. (2019) avaliaram os efeitos da ensilagem e do tempo de armazenamento sobre o valor nutritivo de silagens de capim, composta por forrageiras temperadas (Lolium perene e Alopecurus pratensis), ou de milho. Após 42 dias de fermentação, foram encontradas reduções de $15 \%$ dos teores de FDN para as silagens de milho e de $11 \%$ para as silagens de capim. Também foram observadas perdas MS significativas para os dois tratamentos avaliados. No entanto, constatou-se aumento discreto dos conteúdos de energia liquida para a produção de leite, na ordem de 5,9 para 6,0 MJ / kg de MS nas silagens de capim e de 6,7 para 6,9 MJ/kg de MS nas silagens de milho. Portanto, a ensilagem pode resultar em pequenas elevações no conteúdo de energia liquida das forrageiras. Vale ressaltar que as perdas pelo processo fermentativo (MS) resultam em perdas de energia totais no sistema, e que os resultados discutidos relacionam-se exclusivamente ao melhor aproveitamento energético por kg de MS da silagem. 


\section{Outros componentes modificados pelo processo fermentativo}

A ensilagem e o tempo de armazenamento no silo também estão relacionados com modificações em outros componentes nutricionais que poderiam contribuir para melhorar o aproveitamento energético das silagens. Como exemplo, cita-se os trabalhos que constataram elevações na digestibilidade ruminal do amido nos materiais após a ensilagem (Saylor et al., 2021) e de forma gradativa com o aumento do tempo de armazenamento (Kung Junior et al., 2018).

No trabalho previamente discutido conduzido por Köhler et al. (2019), não foram avaliados e nem considerados os teores de digestibilidade ruminal do amido para realizar os calculos de estimativa de concentração de energia. Dessa forma, o aumento da concentração de energia constatado de fato se relacionou com as modificações nas frações fibrosas nesse caso. Todavia, é importante destacar a magnitude e a relevência das elevações nos valores de digestibilidade ruminal do amido descritos na literatura. A maior parte desses estudos avaliaram silagens com a planta inteira do milho.

Ferraretto et al. (2015) demonstraram que a digestibilidade ruminal in vitro do amido aumentou de $61,7 \%$ no material original para $83,8 \%$ nas silagens de milho com 240 dias de estocagem. Esses valores representam um aumento de 22,1 unidades percentuais e ocorreu de forma gradual (linear) ao longo do período de armazenamento no silo. Resultados relevantes também foram observados por Saylor et al. (2021), ao comparar a digestibilidade ruminal do amido da planta inteira do milho antes e após a ensilagem. Os autores constataram 19,6\% de aumento na digestibilidade ruminal do amido dos materiais com apenas 30 dias de fermentação no silo.

Segundo Hoffman et al. (2011), o aumento da digestibilidade do amido após a ensilagem ocorre devido a degradação da matriz proteica que envolve os granulos de amido no endosperma dos grãos. $\mathrm{O}$ principal mecanismo envolvido nesse processo parecer ser a proteolíse que ocorre pela ação das proteases bacterianas (60\%) e das enzimas vegetais ativas (30\%) (Junges et al., 2017). A atuação desses mecanismos são confirmadas pelas elevações nos teores de nitrogenio amoniacal, $\mathrm{pH}$ e na solubilidade das frações proteicas dos meterias submetidos ao processo de ensilagem e ao tempo de armazenamento prolongado (Kung Junior et al., 2018). Destaca-se que os teores de nitrogenio amoniacal e pH tem relação direta com consumo e desempenho dos animais (Huhtanen et al., 2003; Tharangani et al., 2021) e que o aumento da solubilidade da proteína em sí também é relevante, pois modifica a forma como esse nutriente é metabolizado pelos animais. Portanto, além da hidrólise das hemiceluloses, outros mecanismos desencadeados pelo processo de ensilagem e armazenamento prolongado também podem modificar importantes aspectos nutricionais dos alimentos volumosos.

\section{Considerações finais}

A qualidade do processo fermentativo é determinante nas consequências da ensilagem sobre os componentes fibrosos dos alimentos volumosos. Nos processos fermentativos que resultam em maiores perdas de MS geralmente ocorrem elevações nos teores de fibra das silagens. Entretanto, nos processos fermentativos de maior qualidade geralmente observa-se redução da fibra, devido ao processo de hidrolise ácida das hemiceluloses.

A hidrólise ácida das hemiceluloses também pode reduzir a digestibilidade da fibra e, ao mesmo tempo, elevar o aproveitamento energético das silagens. Além disso, deve-se considerar que outros componentes nutricionais também podem ser modificados pelo processo fermentativo e melhorar esse aproveitamento.

\section{Referências bibliográficas}

Alves, A. R., Pascoal, L. A. F., Cambuí, G. B., Trajano, J. S., Silva, C. M., \& Gois, G. C. (2016). Fibra para ruminantes: Aspecto nutricional, metodológico e funcional. PUBVET, 10(7), 513-579. https://doi.org/10.22256/pubvet.v10n7.568-579.

Ávila, C. L. S., Pinto, J. C., Sugawara, M. S., Silva, M. S., \& Schwan, R. F. (2008). Qualidade da silagem de cana-de-açúcar inoculada com uma cepa de Lactobacillus buchneri. Acta Scientiarum. Animal Sciences, 30(3), 255-261.

Bolsen, K. K., Ashbell, G., \& Weinberg, Z. G. (1996). Silage fermentation and silage additives-Review. Asian-Australasian Journal of Animal Sciences, 9(5), 483-494. 
https://doi.org/https://doi.org/10.5713/ajas.1996.483

Bueno, J. L., Bolson, D. C., Jacovaci, F. A., Gomes, A. L. M., Ribeiro, M. G., Bueno, A. V. I., Jobim, C. C., \& Daniel, J. L. P. (2020). Storage length interacts with maturity to affect nutrient availability in unprocessed flint corn silage. Revista Brasileira de Zootecnia, 49, 1-14. https://doi.org/10.37496/RBZ4920190247.

Cherney, D. J. R., Cherney, J. H. \& Cox, W. J. (2007). Forage quality differences of corn hybrids as influenced by ensiling. Forage Graz-inglands. Doi: https://doi.org/10.1094/FG-2007-0918-01-RS.

Del Valle, T. A., Antonio, G., Zenatti, T. F., Campana, M., Zilio, E. M. C., Ghizzi, L. G., Gandra, J. R., Osório, J. A. C., \& Morais, J. P. G. (2018). Effects of xylanase on the fermentation profile and chemical composition of sugarcane silage. The Journal of Agricultural Science, 156(9), 1123-1129. https://doi.org/10.1017/S0021859618001090.

Der Bedrosian, M. C., Nestor Jr, K. E., \& Kung Junior, L. (2012). The effects of hybrid, maturity, and length of storage on the composition and nutritive value of corn silage. Journal of Dairy Science, 95(9), 5115-5126. https://doi.org/10.3168/jds.2011-4833.

Dewar, W. A., McDonald, P., \& Whittenbury, R. (1963). The hydrolysis of grass hemicelluloses during ensilage. Journal of the Science of Food and Agriculture, 14(6), 411-417. https://doi.org/10.1002/jsfa.2740140610.

Ferraretto, L. F., Shaver, R. D., Massie, S., Singo, R., Taysom, D. M., \& Brouillette, J. P. (2015). Effect of ensiling time and hybrid type on fermentation profile, nitrogen fractions, and ruminal in vitro starch and neutral detergent fiber digestibility in whole-plant corn silage. The Professional Animal Scientist, 31(2), 146-152. https://doi.org/10.15232/pas.2014-01371.

Gerlach, K., Pfau, F., Pries, M., Hünting, K., Weiß, K., Richardt, W., \& Südekum, K. (2018). Effects of length of ensiling and maturity group on chemical composition and in vitro ruminal degradability of whole-crop maize. Grass and Forage Science, 73(3), 599-609. https://doi.org/10.1111/gfs.12362.

Hallada, C. M., Sapienza, D. A., \& Taysom, D. (2008). Effect of length of time ensiled on dry matter, starch and fiber digestibility in whole plant corn silage. Journal of Dairy Science, 91(Suppl 1), 30. https://doi.org/Hallada, C. M., S

Herrmann, C., Heiermann, M., \& Idler, C. (2011). Effects of ensiling, silage additives and storage period on methane formation of biogas crops. Bioresource Technology, 102(8), 5153-5161. https://doi.org/10.1016/j.biortech.2011.01.012.

Hoffman, P. C., Esser, N. M., Shaver, R. D., Coblentz, W. K., Scott, M. P., Bodnar, A. L., Schmidt, R. J., \& Charley, R. C. (2011). Influence of ensiling time and inoculation on alteration of the starch-protein matrix in high-moisture corn. Journal of Dairy Science, 94(5), 2465-2474. https://doi.org/http:dx.doi.org/10.3168/jds.2010-3562.

Huhtanen, P., Nousiainen, J. I., Khalili, H., Jaakkola, S., \& Heikkilä, T. (2003). Relationships between silage fermentation characteristics and milk production parameters: analyses of literature data. Livestock Production Science, 81(1), 57-73. https://doi.org/10.1016/S0301-6226(02)00195-1.

Hunt, C. W., Kezar, W., Hinman, D. D., Combs, J. J., Loeshe, J. A., \& Moen, T. (1993). Effects of hybrids and ensiling with and without a microbial inoculant on the nutritional characteristics of whole-plant corn. Journal of Animal Science, 71, 38-43. Doi: https://doi.org/10.2527/1993.71138x

Junges, D., Morais, G., Spoto, M. H. F., Santos, P. S., Adesogan, A. T., Nussio, L. G., \& Daniel, J. L. P. (2017). Influence of various proteolytic sources during fermentation of reconstituted corn grain silages. Journal of Dairy Science, 100(11), 9048-9051. https://doi.org/10.3168/jds.2017-12943.

Köhler, B., Taube, F., Ostertag, J., Thurner, S., Kluß, C., \& Spiekers, H. (2019). Dry-matter losses and changes in nutrient concentrations in grass and maize silages stored in bunker silos. Grass and Forage Science, 74(2), 274-283. https://doi.org/10.1111/gfs.12430.

Kung Junior, L., Shaver, R. D., Grant, R. J., \& Schmidt, R. J. (2018). Silage review: Interpretation of chemical, microbial, and organoleptic components of silages. Journal of Dairy Science, 101(5), 4020-4033. https://doi.org/10.3168/jds.2017-13909.

Leão, G. F. M., Jobim, C. C., Neumann, M., Horst, E. H., Santos, S. K., Venancio, B. J., \& Santos, L. C. (2017). Nutritional composition and aerobic stability of winter cereal silage at different storage times. Acta Scientiarum. Animal Sciences, 39, 131-136. https://doi.org/10.4025/actascianimsci.v39i2.34270.

Lynch, J. P., Baah, J., \& Beauchemin, D. K. A. (2015). Conservation, fiber digestibility, and nutritive value of corn harvested at 2 cutting heights and ensiled with fibrolytic enzymes, either alone or with a ferulic acid esterase-producing inoculant. Journal of Dairy Science, 98(1214-1224). 
https://doi.org/http://dx.doi.org/10.3168/jds.2014-8768.

Mason, P. M., \& Stuckey, D. C. (2016). Biofilms, bubbles and boundary layers-A new approach to understanding cellulolysis in anaerobic and ruminant digestion. Water Research, 104, 93-100. https://doi.org/10.1016/j.watres.2016.07.063.

McDonald, P. (1981). The biochemistry of silage. John Wiley \& Sons, Ltd.

Mertens, D. R. (1994). Regulation of Forage Intake. In J. R. Fahey (Ed.), Forage Quality, Evaluation, and Utilization (pp. 450-493). American Society of Agronomy.

Muck, R E, Nadeau, E. M. G., McAllister, T. A., Contreras-Govea, F. E., Santos, M. C., \& Kung Junior, L. (2018). Silage review: Recent advances and future uses of silage additives. Journal of Dairy Science, 101(5), 3980-4000. https://doi.org/10.3168/jds.2017-13839.

Muck, Richard E. (2010). Silage microbiology and its control through additives. Revista Brasileira de Zootecnia, 39(Supl), 183-191. https://doi.org/http://dx.doi.org/10.1590/S1516-35982010001300021.

Naeini, S. Z., Emami, N. K., Rowghani, E., \& Bayat, A. (2014). Influence of ensiling time on chemical composition, fermentation characteristics, gas production and protein fractions of sweet sorghum silage. Research Opinions in Animal and Veterinary Sciences, 4(6), 286-293.

NRC. (2000). Nutrient Requirements of Beef Cattle (7th rev.). Natl. Acad. Press.

O'sullivan, A. C. (1997). Cellulose: the structure slowly unravels. Cellulose, 4(3), 173-207. https://doi.org//10.1023/A:1018431705579.

Sanderson, M. A. (1993). Aerobic stability and in vitro fiber digestibility of microbially inoculated corn and sorghum silage. Journal of Animal Science, 71, 505-514. Doi: https://doi.org/10.2527/1993.712505x

Santos, M. C., \& Kung Junior, L. (2016). The effects of dry matter and length of storage on the composition and nutritive value of alfalfa silage. Journal of Dairy Science, 99(7), 5466-5469. https://doi.org/10.3168/jds.2016-10866.

Saylor, B. A., Diepersloot, E. C., Heinzen Jr, C., McCary, C. L., \& Ferraretto, L. F. (2021). Effect of kernel breakage on the fermentation profile, nitrogen fractions, and in vitro starch digestibility of whole-plant corn silage and ensiled corn grain. JDS Communications, 2(4), 191-195. https://doi.org/10.3168/jdsc.2021-0093.

Schmidt, R. J., Hu, W., Mills, J. A., \& Kung Junior, L. (2009). The development of lactic acid bacteria and Lactobacillus buchneri and their effects on the fermentation of alfalfa silage. Journal of Dairy Science, 92(10), 5005-5010. https://doi.org/10.3168/jds.2008-1701.

Silva, L. D., Pereira, O. G., Silva, T. C., Leandro, E. S., Paula, R. A., Santos, S. A., Ribeiro, K. G., \& Valadares Filho, S. C. (2018). Effects of Lactobacillus buchneri isolated from tropical maize silage on fermentation and aerobic stability of maize and sugarcane silages. Grass and Forage Science, 73(3), 660-670. https://doi.org/10.1111/gfs.12360.

Tharangani, R. M. H., Yakun, C., Zhao, L. S., Ma, L., Liu, H. L., Su, S. L., Shan, L., Yang, Z. N., Kononoff, P. J., \& Weiss, W. P. (2021). Com silage quality index: An index combining milk yield, silage nutritional and fermentation parameters. Animal Feed Science and Technology, 273, 114817. https://doi.org/10.1016/j.anifeedsci.2021.114817.

Udén, P. (2018). Fresh and ensiled forage plants - total composition, silage losses and the prediction of silage composition from the crop. Grass and Forage Science, 73(2), 420-431. https://doi.org/10.1111/gfs.12328.

Van Soest, P. J. (1994). Nutritional ecology of the ruminant. In Nutritional Ecology of the Ruminant (Vol. 1, Issue 2). Cornell University Press. https://doi.org/10.7591/9781501732355

Weinberg, Z. G., \& Chen, Y. (2013). Effects of storage period on the composition of whole crop wheat and corn silages. Animal Feed Science and Technology, 185(3), 196-200.

Woolford, M. K., \& Pahlow, G. (1998). The silage fermentation. Springer.

Young, K. M., Lim, J. M., Der Bedrosian, M. C., \& Kung Jr, L. (2012). Effect of exogenous protease enzymes on the fermentation and nutritive value of corn silage. Journal of Dairy Science, 95, 66876694. Doi: https://doi.org/10.3168/jds.2012-5628

\section{Histórico do artigo:}

Recebido: 16 de setembro de 2021

Aprovado: 11 de outubro de 2021

Disponível online: 13 de novembro de 2021
Licenciamento: Este artigo é publicado na modalidade Acesso Aberto sob a licença Creative Commons Atribuição 4.0 (CC-BY 4.0), a qual permite uso irrestrito, distribuição, reprodução em qualquer meio, desde que $\mathrm{o}$ autor e a fonte sejam devidamente creditados. 